\title{
VIOLÊNCIA E PODER NA CONTEMPORANEIDADE: UMA EXPERIÊNCIA ENTRE PESQUISA E EXTENSÃO
}

\author{
João Santos Cardoso', Elton Silva Salgado ${ }^{2}$, Elton Moreira Quadros ${ }^{3}$ \\ Fernando de Cássia Meira Oliveira ${ }^{4}$ Julimar Barros Pereira ${ }^{5}$
}

\section{RESUMO}

O artigo relata a criação do Núcleo Avançado de Estudos da Contemporaneidade (NUVIP) e discorre sobre como o Projeto de Pesquisa e Estudo sobre Violência Urbana em Vitória da Conquista desencadeou de forma natural uma série de atividades de extensão, o que resultou na formulação de um projeto de extensão intitulado Violência na Contemporaneidade, apresentado em 2010 à Pró-Reitoria de Extensão e Assuntos Comunitários (PROEX) e à Gerência de Extensão e Assuntos Culturais (GEAC), atualmente, em fase de execução. Tendo como método o relato de experiência, o texto evidencia algumas estratégias e técnicas adotadas pelo núcleo que permitiram socializar e estender à comunidade em geral os resultados de suas pesquisas e discussões

\footnotetext{
${ }^{1}$ Doutor em Filosofia pela Pontifícia Universidade Gregoriana (Roma, 2002). Bispo da Diocese de São Raimundo Nonato - PI. E-mail: cardos.sj@gmail.com

${ }^{2}$ Mestrando em Letras: Cultura, Educação e Linguagens (UESB). Vice-coordenador e pesquisador vinculado ao NUVIP. E-mail: elton.mailer@gmail.com.

${ }_{3}^{3}$ Professor substituto da UESB. Mestrando em Memória: Linguagem e Sociedade (UESB). Pesquisador vinculado ao NUVIP. E-mail: eltonquadros@yahoo.com.br.

${ }^{4}$ Professor do Instituto de Filosofia Nossa Senhora das Vitórias (IFNSV), membro da Comissão de Atualização Acadêmica da OAB - Subseção de Vitória da Conquista e Assessor Jurídico da Empresa Municipal de Urbanização de Vitória da Conquista (EMURC). Graduado em Direito pela UESB. Membro do NUVIP. E-mail: fernandocmo@yahoo.com.br

${ }_{5}^{5}$ Advogado da Prefeitura Municipal de Vitória da Conquista (PMVC). Graduado em Direito pela UESB. Membro do NUVIP. E-mail: julimarbarrospereira@bol.com.br.
}

\begin{tabular}{l|l|l|l|l}
\hline Revista Extensão \& Cidadania & Vitória da Conquista & v. 1, n. 1 & p. 241-256 & jan./jun. 2013 \\
\hline
\end{tabular}


para provocar reflexões, bem como a mudança de métodos e a ampliação da visão a respeito do objeto pesquisado. A pesquisa adota, inicialmente, uma metodologia quantitativa e semiqualitativa no tratamento do objeto violência. A revisão de bibliografia permitiu ao grupo uma abordagem mais teórica do objeto, como também alargou a compreensão sobre o tema, enfocado em seus aspectos filosóficos, éticos, políticos e antropológicos no conjunto da mentalidade cultural que caracteriza o tempo atual.

Palavras-chave: Hannah Arendt. NUVIP. Poder. Violência.

\begin{abstract}
The following article discusses NUVIP's creation and also talks about how the Research Project and Study on Urban Violence in Vitória da Conquista naturally started a series of education outreach activities that ended in the formulation of an outreach program entitled Violence in Contemporary, presented to PROEX/GEAC in 2010, and which is being performed nowadays. With the experience report method in mind, the text clarifies some strategies and tecniques adopted by NUVIP that would permit to socialize and to extend the results of its researchs, discussions and reflections to the whole community, and how is posible to change methods and enlarge the vision about the object as well. Inicially, a quantitative and partially qualitative methodology was adopted regarding the object violence, and the literature review allowed the group theoretically approach the object besides spread the comprehension about the topic, that is focused in philosophical, ethical, political, and anthropological aspects, considering cultural mentality in the current days.
\end{abstract}

Keywords: Hannah Arendt. NUVIP. Power. Violence.

\title{
Introdução
}

O Núcleo Avançado de Estudos da Contemporaneidade (NUVIP) surgiu no segundo semestre de 2006, com aprovação do Departamento de Filosofia e Ciências Humanas (DFCH), e, em 21 de novembro de 2006, o Núcleo realizou um Encontro sobre Violência e Poder na Contemporaneidade, contando com a participação de 100 discentes da Universidade Estadual do Sudoeste da Bahia (UESB) e de outras Instituições de Ensino Superior de Vitória da Conquista. A ideia da criação do Núcleo surgiu após a constatação, pelos acadêmicos, da carência de pesquisa na área de Ciências 
Sociais Aplicadas. Levando-se em consideração uma temática que fosse suficientemente abrangente para alcançar os campos teóricos e de aplicação prática e se deparando com o vertiginoso aumento dos números e estatísticas que envolviam a questão da violência na cidade de Vitória da Conquista, os integrantes elegeram a temática "Violência e Poder" como objeto de estudo. Por tal motivo, o NUVIP, em seu projeto inicial, possuía a nomenclatura de Núcleo Interdisciplinar de Estudo e Pesquisa sobre Violência e Poder na Contemporaneidade.

Como o próprio nome já esclarecia, a proposta do NUVIP era a de alcançar acadêmicos dos mais diversos níveis e das mais diversas disciplinas das Ciências Sociais e da Filosofia, os quais tivessem por objetivo o estudo, a compreensão e a pesquisa sobre a temática adotada. No início, o grupo contava com estudantes do Curso de Direito da UESB e professores das disciplinas Filosofia do Direito, Introdução à Filosofia, Direitos Humanos e Cidadania e Sociologia Jurídica, ligados aos Departamentos de Ciências Sociais Aplicadas (DCSA) e de Filosofia e Ciências Humanas (DFCH) da UESB.

Em fevereiro de 2007, o Núcleo foi cadastrado entre os grupos de pesquisa do Conselho Nacional de Desenvolvimento Científico e Tecnológico (CNPq) e, em março de 2007, submeteu-se ao Edital 006/2007 e apresentou à Pró-Reitoria de Pesquisa e Graduação (PPG) e à Gerência de Pesquisa (GP) da UESB o Projeto de Pesquisa e Estudo sobre Violência Urbana em Vitória da Conquista. Aprovado e homologado pela Resolução do CONSEPE 038/2007. O projeto foi desenvolvido durante dois anos e teve seus resultados divulgados em diversos eventos, alguns realizados pela própria UESB, a exemplo do VIII Colóquio Nacional e I Colóquio Internacional do Museu Pedagógico. Em pouco tempo de existência, o grupo se expandiu e, com o avançar das pesquisas e discussões, passou a desenvolver atividades de extensão e contou também com membros de outras Instituições de Ensino Superior de Vitória da Conquista, ligados aos cursos de História, Direito, Psicologia e Filosofia.

Atentando para a importância de fundamentar teoricamente os estudos que propunha, o NUVIP elegeu entre a lista bibliográfica do projeto de pesquisa alguns referenciais teóricos que foram 
fundamentais para a reestruturação do Núcleo na forma em que se encontra atualmente. Autores como Hannah Arendt, Gilles Lipovetsky e Zygmunt Bauman, entre outros, lançaram luzes para a compreensão da temática do poder e da violência e da forma que tais problemas se manifestam hodiernamente. Esses autores permitiram também ampliar o leque de discussões e fazer com que essa temática se torne mais uma das várias linhas de pesquisa do NUVIP.

A percepção dos problemas da era atual conduziu os membros do núcleo a ampliar o foco da pesquisa, integrando o tema da Contemporaneidade e suas vicissitudes ao seu campo de estudo. Assim, o NUVIP passou a usar a nomenclatura "Núcleo Avançado de Estudos da Contemporaneidade". A abrangência do tema não permitiu apenas uma maior abertura dos campos de discussão, mas, sobretudo, a inserção de novos membros, das mais diversas áreas, que contribuem, sob vários aspectos, com a proposta atual do grupo, qual seja, a de descortinar os problemas da era atual e estabelecer algumas linhas de pesquisa, entre as quais se destacam: a Violência na Contemporaneidade; Ética, Direitos Humanos e Alteridade; Sociabilidade e Contemporaneidade.

O resultado dos debates e o produto das discussões de seus membros levaram o NUVIP a divulgar suas pesquisas, por meio da participação em congressos - com a publicação em anais e artigos - e da realização de atividades de extensão, como seminários, simpósios, palestras e minicursos. O Núcleo sempre se propôs a expandir o conhecimento produzido no seio acadêmico, com o objetivo de darlhe uma aplicação prática capaz de amenizar a realidade social que problematizou e serviu de fundamento para as pesquisas realizadas. Assim, o NUVIP conseguiu alcançar, por diversas vezes, não somente o público acadêmico, mas também a sociedade em geral. É comum e constante a participação de religiosos, advogados, pedagogos, psicólogos, geógrafos que, embora distantes do universo acadêmico, preocupam-se com as questões sociais e contribuem, sobremaneira, com enriquecedoras colocações e posições para a ampliação do 
eixo de atuação do grupo. Nesse sentido, é possível perceber que o Núcleo fomenta o debate e a socialização dos saberes, para estendêlos além dos muros da Universidade e alcançar grupos e atores sociais que se encontram, muitas vezes, amplamente distantes dos debates acadêmicos, mas que são, em verdade, o fundamento de toda pesquisa de caráter social.

\section{Referencial Teórico}

O Projeto Inicial do Núcleo que, na formulação central de seu objeto temático, estuda a violência e o poder na contemporaneidade, evoca uma distinção gramatical entre estes termos, estabelecida pela filósofa política alemã Hannah Arendt em seu livro On Violence (Sobre a violência), publicado nos Estados Unidos no final da década de 60 . Como esta obra serviu de referencial teórico para o projeto de pesquisa, convém esboçar em breves linhas o contexto histórico em que ela está situada, bem como apresentar as distinções conceituais a respeito do termo violência.

O referido livro de Hannah Arendt reflete o ambiente cultural, histórico e social dos anos sessenta. Os cientistas históricos costumam tratar o século XX como um período de mudanças rápidas e extremas, momento em que nada mais poderia ser tratado pelos termos do habitual ou do tradicional. Por outro lado, é preciso notar que o século passado reuniu as maiores catástrofes da nossa história e que, graças aos conflitos de ordem mundial e pelos inúmeros mortos registrados, o período terminou como o mais violento de todos os séculos. Por isso, muitos historiadores afirmam que o século XX representou o colapso da civilização, cuja calamidade principal assentou-se em três elementos: a depressão, a guerra e o fascismo (HOBSBAWM, 2000).

Atenta a esses aspectos, Hannah Arendt, em seu livro Sobre a violência, faz uma análise das situações negativas e desastrosas que envolvem o tempo posterior à Segunda Guerra Mundial (1939-1945) e assinala o início da Guerra Fria. Todavia, esse momento é também conhecido pela Revolução Cultural da China na Era Mao Tse-Tung 
(1949-1976) e pela Revolução Cubana (1953-1959), bem como por conflitos pela independência de países da África e da Ásia e pela Guerra do Vietnã (1965-1973) e pela rebelião estudantil em maio de 1968; esse período ainda é famoso pelo surgimento da nova esquerda e pela opção de enfrentamento à guerrilha, que, no Brasil de Garrastazu Médici (1969-1974), coincide com o acirramento da repressão militar, consubstanciado pelo Ato Institucional Número 5.

Arendt (1994) considera a violência uma “ação contrária” à ordem moral, jurídica ou política, que, em consequência desse caráter, foi muitas vezes exaltada pelos Estados totalitários e assassinos, bem como pelos movimentos de esquerda. Nesse contexto, o século XX é visto como aquele que encontrou na violência o modo de multiplicação de sua revolução tecnológica e que ocorreu o avanço da nova esquerda, baseada no princípio de Mao Tse Tung, para quem todo o poder brotaria do cano de uma arma. Contudo, em outra vertente, assistiu-se igualmente ao uso de outros meios de resistência à opressão, como a desobediência civil e o que ela denomina de "lúcido humanismo", que seria uma retomada do sentido sobre a política, o viver socialmente, uma vez que "o homem não deve a sua existência a si mesmo, tanto como membro da espécie quanto como indivíduo" (ARENDT, 1994, p. 30).

Dessa forma, Arendt (1994) debruça-se sobre a violência em sua dimensão política e empreende uma análise linguístico-gramatical de seu conceito. A autora chama a atenção do leitor para a diferença de significado entre a palavra "violência" e os termos "poder", "vigor", "força" e "autoridade", o que lhe permitirá rechaçar a confusão gramatical existente em filosofia política, que, de forma indistinta, usa os referidos conceitos como se eles fossem sinônimos e se referissem aos mesmos fenômenos.

Já que no contexto teórico e na linguagem cotidiana o termo violência é empregado de forma confusa e imprecisa, lançar mão do esclarecimento gramatical empreendido por Arendt (1994) fezse necessário em razão da importância filosófica e teórica que tais distinções representam para a pesquisa sobre Violência e Poder na Contemporaneidade. 
O termo violência é largamente usado e, por isso, sujeito a confusões. A recorrência incessante da palavra violência ao unificar fatos tão diversos entre si, sob um mesmo conceito, cria ilusão e gera confusões, o que permite discursos contraditórios sobre os fenômenos que ela representa. A palavra violência não é unívoca, mas polissêmica e tem uma conotação tão forte que se torna difícil encontrar uma definição consensual a respeito do seu uso. Por sua vez, o fenômeno da violência por ser multifacetado e difuso, cria dificuldades na elaboração de seu conceito, pois existem várias formas de perceber o grau de suas manifestações e de sua tolerância, em que diversos fatores de ordem cultural, dos valores, da posição social, das circunstâncias históricas interferem na sua percepção. No imaginário popular e na vida cotidiana, usa-se a palavra violência apenas em seus aspectos físicos, para se referir a homicídios, torturas, agressões, lesões corporais, maus tratos, sofrimento, mutilações, ferimentos, mortes, roubos e crimes em geral.

Outras formas diferenciadas de percepção da violência também estão presentes nos textos acadêmicos que tentam definir o fenômeno em estudo. A Organização Mundial da Saúde compreende a violência como "[...] uso intencional da força física ou do poder, real ou em ameaças, contra si, contra outra pessoa ou contra grupos ou comunidades, que resulte ou venha resultar em lesão, morte, dano psicológico, privação [...]" (OMS, 2002). Michaud (1989) define-a como uma ação direta ou indireta que cause danos a uma ou a várias pessoas, seja em sua integridade física, seja em sua integridade moral, em suas posses e em suas representações simbólicas. Tanto o uso cotidiano como as definições apresentadas limitam o termo violência, basicamente, à agressão ao corpo em suas várias dimensões, embora os dois conceitos apresentados ultrapassem a agressão propriamente física.

Não obstante, tal distinção persiste no cotidiano assim como em plano teórico, como já observara Arendt (1994), a tendência em identificar ou associar a violência aos termos poder, vigor, força e autoridade, como se estas palavras fossem sinônimas e tivessem a mesma função lógica 
de indicar "quem domina quem". Ademais, tal confusão contribui por reduzir o espaço público da ação política à simples questão de dominação. Dessa reflexão deriva ainda a crítica arendtiana ao pensamento marxista que enaltece a violência como motora da história e não dá o devido valor à argumentação racional como o instrumento político mais genuíno para a resolução dos conflitos humanos e sociais (ARENDT, 1994). Segundo Arentd (1994, p. 36), o poder não se identifica com a violência, pois aquele "corresponde à habilidade humana não apenas para agir, mas para agir em concerto", ao passo que violência diz respeito ao uso de meios e instrumentos com a finalidade de multiplicar e potenciar o vigor natural. É por isso que a violência tem um caráter instrumental e aproxima-se não semanticamente, mas fenomenologicamente de vigor, que, por sua vez, se refere a uma habilidade individual, a uma propriedade inerente ao caráter de um objeto ou de uma pessoa. Entretanto, nem mesmo vigor se confunde com força, pois à medida que aquele indica uma propriedade individual, a força indica uma qualidade coletiva, algo como energia, firmeza, ânimo liberado pelos movimentos físicos e sociais.

Se vigor não se identifica com força, igualmente autoridade não se confunde com alguma forma de poder ou violência, uma vez que a essência da autoridade se caracteriza pelo reconhecimento moral que um determinado líder adquire diante de um grupo (ARENDT, 1994). Em razão disso, torna-se incompatível, no exercício da autoridade, tanto o uso da força como o do poder, já que a autoridade se caracteriza pela adesão quase inquestionável do grupo à sua liderança, e torna indispensável tanto a argumentação racional como o uso da força mediante violência (ARENDT, 1994). Dessa forma, a ação violenta transforma-se em um instrumento de poder, de imposição da vontade de um indivíduo sobre o outro, mas jamais deve ser considerada a essência do governo. Em razão de seu caráter instrumental, a violência pode ser apenas justificada, em situações de exceções, em vista do fim para o qual ela é usada e que se deseja atingir, mas jamais legitimada. Só o poder pode ser legitimado porque deriva do consenso de comunidades políticas (ARENDT, 2000). 
Arendt reluta em associar violência com o poder ou com o Estado. Em A condição bumana (2005a), ela caracteriza a violência como modos pré-políticos de lidar com as pessoas, típicos da vida fora da polis, característicos do ambiente do lar ou da família, na qual o chefe da casa reinava com poderes incontestes e despóticos. Enquanto poder diz respeito à aquisição do consenso mediante o diálogo, violência supõe o uso da força para ordenar ao invés de persuadir. Por isso, a violência aumenta nos lugares onde ocorre a redução da esfera pública. Lá onde o poder participativo perde consistência e deteriora o espaço político do exercício da cidadania, com a consequente ausência da ação e do diálogo, tende a instaurar-se a violência (ARENDT, 2005a, 2005b). Eis, portanto, não ser razoável nem realista esperar de pessoas que não têm a mínima noção do bem público que se comportem de maneira não violenta (ARENDT, 2000).

Além desse esclarecimento linguístico-conceitual, é forçoso ressaltar a contribuição de Arendt para a desnaturalização, despersonificação e desdemonização da violência. Ela desloca a abordagem desse fenômeno de um plano meramente individual para um plano político e social. Arendt (1994) recusa-se a associar a ação política com a luta pela sobrevivência, como ocorre nos estudos de Nietzsche e de Bergson, que, ao transpor as mesmas categorias organicistas para a interpretação das questões políticas, justifica biologicamente a violência, e lhe atribui uma dimensão e expressão expansionista de vitalidade. Segundo Arendt (1994), nem a violência nem o poder são fenômenos naturais ou uma manifestação do processo vital, pois ambos pertencem ao âmbito político das ações humanas. Dessa forma, a violência assume apenas uma potencialidade instrumental que funciona como meio para chamar a atenção do público ao dramatizar queixas e reagir ao decréscimo do poder. Em virtude dessa instrumentalidade, a violência perde o seu caráter bestial, irracional, mágico ou demoníaco que, frequentemente, lhe é atribuído. Tanto na vida pública como na particular, o fato de agir com rapidez e prontidão não torna um ato violento irracional, mas pode constituir 
num "único modo de re-equilibrar as balanças da justiça" (ARENDT, 1994, p. 48).

Ao desnaturalizar a violência, Arendt segue uma linha de raciocínio que concorre também para a sua despersonificação e desdemonização. Após acompanhar o julgamento de Adolf Eichmann em Jerusalém, Arendt publicou, em 1963, Eichmann a Jerusalém: Rapport sur la Banalité du Mal. Nessa obra, ela concluiu que aquele principal mentor do Holocausto, longe de apresentar uma personalidade sádica e pervertida, como afirmavam os psiquiatras da acusação - ou antes de ser a encarnação do próprio mal, como consideravam os religiosos judeus -, era, na verdade, um homem comum e extremamente normal, um homem de carne e osso, mas sem consistência própria, um típico burocrata que se limitara a cumprir ordens, com zelo, sem capacidade de discernir o bem do mal, ou mesmo de ter contrição. Aquele burocrata do extermínio dos judeus não era um demônio nem um poço de maldade, mas alguém terrivelmente normal, incapaz de pensar por conta própria, que seguia mecanicamente regras e perdia a própria capacidade de indignar-se frente à banalização do mal. Assim, Arendt apontaria apenas para a complexidade da natureza humana que, em determinados contextos, tende a acostumar-se com o mal, a naturalizálo, a torná-lo uma coisa banal e corriqueira. Isso se torna realidade especialmente quando o sofrimento, a tortura, a dor e a própria prática do mal não causam mais indignação. Então, na esteira do pensamento arendtiano, é possível afirmar que a violência não decorre de uma natureza humana perversa, violenta, embora ela pareça naturalizarse mediante a indiferença que as pessoas assumem nos tempos hipermodernos, frente à banalização da violência e sua redução a um espetáculo televisivo.

A violência pode encontrar explicações em um plano psíquico e individual, como se houvesse uma tendência natural do ser humano a agir mediante o uso da força para conseguir determinados objetivos em determinados contextos; também é possível que se encontre no ser humano certo fascínio para agir de forma violenta em função de 
possíveis fatores genéticos, de traços específicos de personalidade ou em razão da própria vitalidade da espécie. Entretanto, esses dois tipos de abordagem não são suficientes para dar conta da violência nas sociedades urbanas de nossos tempos. Nesse sentido, a desnaturalização, despersonificação e desdemonização que Arendt opera sobre a violência têm ajudado o NUVIP a estudar esse fenômeno em suas vertentes antropológicas, psicológicas, sociológicas, econômicas, políticas, jurídicas e filosóficas, ao permitir a cada pesquisador servir-se das diversas contribuições oriundas das ciências humanas e sociais para melhor compreender as manifestações da violência em nossas cidades.

Dessa forma, sem assumir um ecletismo ingênuo e mitigador das diferenças ideológicas, o fenômeno da violência urbana vem sendo estudado sob diversas perspectivas, como: abordagens de vertente marxista que entendem a violência como uma consequência da luta de classes e da nova fase de expansão do neoliberalismo; os enfoques da Escola de Chicago e da perspectiva da Escola de Frankfurt com a denúncia da indústria cultural; elementos da reflexão de Lipovetsky que, ao ressaltar a era do vazio dos tempos hipermodernos, permite compreender a dessubstancialização do sujeito e a emergência de um indivíduo sem conteúdo e sem grandes ideais, reduzido à mera condição de consumidor submetido a um processo de escolha permanente diante de uma quase infinita possibilidade de consumo. Também não foi olvidado o percurso de Bauman em sua Modernidade líquida, termo que usa para exprimir a passagem de uma modernidade "sólida" para uma modernidade "leve", "líquida" marcada pelo individualismo, imediatismo e fluidez das relações, que trouxeram profundas mudanças em todos os setores da vida humana. Com base nessas perspectivas, foi possível perceber a mudança de fisionomia da violência em Vitória da Conquista, enquanto produto de sociedades fragmentadas que atomizam a pessoa humana, minam as relações sociais e o agir coletivo, e aumentam o medo, a insegurança e o sentimento de impotência. 


\section{Metodologia}

Como o processo de maturação das ideias e da própria concepção do projeto de pesquisa foi acontecendo na dinâmica de estabelecimento do grupo, algumas etapas desse processo ganharam aos poucos a sua forma, o que possibilitou uma diversidade de metodologias que, em alguma medida, caracterizam o caráter multidisciplinar do empreendimento que desencadeou as atividades de extensão.

Inicialmente, o Projeto de Pesquisa e Estudo sobre Violência Urbana em Vitória da Conquista, formulado pelo NUVIP, tinha como proposta criar um banco de dados sobre a violência na cidade e mapear suas zonas geográficas e os horários de maior vulnerabilidade e riscos; em razão disso, foi utilizado o método quantitativo na coleta de dados junto à comunidade e instituições, o que permitiu a tabulação dos mesmos, e o método semiqualitativo de análise. Assim, a violência era estudada em sua face mais evidente como fenômeno social relacionado às estatísticas de crimes. Entretanto, a própria revisão bibliográfica prevista no projeto, discutida em reuniões periódicas que buscavam entender as estatísticas e mapear o objeto estudado, permitiu alargar a discussão para compreender a violência de forma mais abrangente em sua vertente teórica. Os ciclos de leituras e as discussões acadêmicas da literatura levantada sobre o tema, as sessões de estudos do ano de 2007 sobre A Violência das Cidades de Yves Pedrazzini, as rodas de conversas sobre a violência urbana em Vitória da Conquista e os ciclos de leituras de 2009 sobre o enfoque arendtiano Sobre a Violência ou, ainda, as leituras de 2010 sobre Bauman permitiram a criação de uma metodologia focada na compreensão teórica e mais abrangente do tema que ainda incluía a questão das estatísticas e dos crimes, entretanto, mais voltada aos aspectos conceituais, simbólicos e filosóficos do problema. 


\section{Atividades de extensão}

Internamente, o Núcleo amadureceu a compreensão da necessidade de socializar e estender à comunidade o resultado de suas reflexões por meio de pequenas atividades de extensão, como eventos, palestras, minicursos e mesas-redondas, que possibilitaram à comunidade externa o acesso a essa reflexão. Entre essas atividades, podemos destacar: o minicurso de extensão sobre $O$ Conceito de Violência em Hannah Arendt, a assessoria na criação de um projeto piloto na Escola Rainha da Paz (Patagônia), voltado para a cultura da paz e da não violência; e a constituição de um grupo de estudo e iniciação à pesquisa com a presença de discentes da UESB e de outras instituições de ensino superior da cidade.

Ao longo de 2011, foram realizadas sessões de leituras com estudantes universitários, profissionais liberais e populares, a fim de refletir sobre obras de pensadores como Zygmunt Bauman, Lipovetsky, Jean-Claude Guillebaud e Emmanuel Lévinas. A metodologia dessas leituras consiste na apresentação das principais características e ideias da obra de cada pensador para a comunidade, graduandos e pessoas de diversas áreas profissionais. Dessa forma, as realizações intercaladas e contínuas das atividades acadêmicas do grupo, as reflexões mais aprofundadas dos temas e as apresentações públicas de livros de pensadores relevantes sobre a temática contribuem para tornar a extensão uma ação de verdadeiro diálogo entre a pesquisa e o ensino. As atividades de extensão são realizadas não como eventos em si próprios, mas como meios para a saída dos lugares comuns da noção de violência para uma melhor compreensão desse tema. Nesse sentido, somente com um aprofundamento paciente e constante será possível abandonar as ideias extremamente arraigadas no senso comum que, recorrentemente, dificultam uma compreensão mais ampliada do fenômeno da violência. 


\section{Minicurso de extensão "O conceito de violência em Hannah Arendt"}

$\mathrm{O}$ minicurso de extensão "O conceito de violência em Hannah Arendt", embora não derivado de um projeto de extensão oficialmente submetido à PROEX, surgiu como desenvolvimento e consequência natural das discussões internas e dos estudos realizados pelo NUVIP. O minicurso referido, foi realizado em 07 de maio de 2010, em parceira com a Ordem dos Advogados do Brasil (OAB), subseção de Vitória da Conquista, que cedeu o auditório da Instituição para o evento, o qual encontrou boa acolhida - primeiramente, por parte da imprensa, que percebeu que o objetivo do NUVIP era justamente alargar as discussões que envolvem o tema da violência, muitas vezes tratada apenas no nível das ocorrências policiais e mascarando, como diz Hannah Arendt, o essencial. Desse modo, foram muitos os sites e blogs de conteúdo que divulgaram o evento, inclusive de outras cidades e em jornais de circulação estadual como o $A$ Tarde, e mesmo em páginas de outros grupos de pesquisas do país interessados na temática ou na produção da autora, como foi o caso do Grupo de Estudos e Arquivo Hannah Arendt, vinculado ao Grupo de Estudos da Violência da Universidade de São Paulo. Além disso, os pesquisadores do grupo foram convidados para entrevistas em emissoras de rádio e TVs locais.

Graças a essa ampla divulgação, o evento atraiu a atenção de um número significativo de estudantes universitários de variadas formações, tanto da UESB quanto de outras instituições de ensino superior de Vitória da Conquista, de representantes de movimentos sociais locais e ainda de pessoas da comunidade interessadas na temática. O alcance do evento favoreceu, inclusive, a realização de ações posteriores que desembocaram na formulação do Projeto de Extensão intitulado "Violência na contemporaneidade", apresentado em 2010 à PROEX/GEAC, sem ônus para a Instituição, aprovado e homologado pela Resolução do CONSEPE N. ${ }^{\circ}$ 90/2010. O projeto encontra-se em fase de execução e, como proposto em seu objetivo, 
está realizando um curso de extensão destinado a universitários e à comunidade em geral, em que se aborda teoricamente e se discute as questões sobre a violência, levando em consideração os aspectos culturais que caracterizam a mentalidade contemporânea.

\section{Considerações Finais}

A exposição delineada mostra que as atividades de extensão decorrem da pesquisa, sem a qual a extensão, para o NUVIP, não se justificaria ou se resumiria a ações sem consistência, voluntaristas, fragmentadas, que reproduzem trabalhos de terceiros, sem consciência reflexiva dos pressupostos teóricos que as fundamentam. Foi muito significativa, no desenvolvimento do texto, a constatação da importância da revisão de literatura e a discussão teórica sobre o tema da violência, pois permitiram ao Núcleo não só uma compreensão mais crítica das questões conceituais e filosóficas que antecedem e configuram aquele problema, como também deram consistência às atividades de extensão, lançando luzes na percepção da violência. Dessa forma, faz-se necessário estreitar a relação entre a pesquisa e a extensão, bem como criar mecanismos de fomento mais flexíveis, capazes de acompanhar e apoiar o dinamismo das atividades de pesquisa e extensão em curso no cotidiano da instituição. Embora seja senso comum na comunidade acadêmica, não é supérfluo lembrar que, por meio da extensão, a universidade estabelece uma relação de proximidade com a comunidade local e regional, e nela se insere, socializando saberes, oferecendo elementos que a ajudam na compreensão e resolução de determinadas questões que a envolvem. 


\section{Referências}

ARENDT, H. Sobre a violência. Rio de Janeiro: Relume Dumará, 1994. - Eichmann em Jerusalém: um relato sobre a banalidade do mal. Trad. José Rubens Siqueira. São Paulo: Companhia das Letras, 1999. . Origens do totalitarismo. São Paulo: Companhia das Letras: 2000. - A condição bumana. 10. ed. Rio de Janeiro: Forense Universitária, 2005a.

- Entre o passado e o futuro: oito exercícios sobre o pensamento político. 5. ed. São Paulo: Perspectiva, 2005b.

BAUMAN, Z. Modernidade líquida. Rio de Janeiro: J. Zahar Editor, 2001. . Confiança e medo na cidade. Rio de Janeiro: J. Zahar Editor, 2009.

ENGELS, F. Teoria da violência. In: NETTO, José Paulo (Org.). Engels. São Paulo: Ática, 1981. (Col. Grandes Cientistas Sociais, v. 17).

HOBSBAWM, E. J. A era dos extremos: o breve século XX. 7. ed. São Paulo: Companhia das Letras, 2000.

LIPOVETSKY, G. A sociedade pós-moralista: o crepúsculo do dever e a ética indolor dos novos tempos democráticos. Baueri/SP: Manole, 2005.

- A era do vazio: ensaios sobre o individualismo contemporâneo. Baueri/SP: Manole, 2007.

MICHAUD, Y. A violência. São Paulo: Ática, 1989.

ORGANIZAÇÃO MUNDIAL DE SAÚDE (OMS). Relatório mundial sobre a violência e saúde. Genebra, 2002.

PEDRAZZINI, Y. A violência das cidades. Petrópolis: Vozes, 2006. 